\title{
Utility Scale Solar Power with Minimal Energy Storage
}

\author{
Qi Luo and Kartik B. Ariyur \\ Purdue University \\ USA
}

\section{Introduction}

Smart grid functionality creating an internet of energy has been a topic of increasing interest. It is opening up several real time functions: pricing, network and consumption tracking, and integration of solar and wind power. The report from Department of Energy (DOE, 2008; 2009) supplies accessible details. At the present time, utilities run coal thermal power plants and nuclear plants as base load (Srivastava \& Flueck, 2009) and use land based gas turbine plants to absorb unexpected demand surges (Nuqui, 2009). Solar energy, though envisioned as one of the panaceas to power from fossil fuels, suffers from two deficiencies: the density of energy available, and the unreliability of power production. Density limits mean solar power will never quite replace coal and nuclear plants for base load. However, the factor that limits penetration of solar power is the unreliability of supply that stems from uncertainty in incident solar radiation. A 100MW plant can produce much less power output in a matter of minutes if a cloud passes over it. It can also jump the other way. This can potentially result in large and undesirable transients being introduced into the grid. Large currents can damage grid equipment, such as power lines or transformers, in a very short period of time. This means that solar power needs backup power in the grid in the form of polluting coal or expensive gas. This is the main reason that grid operators and utilities are reluctant to integrate solar energy into their systems. This also means that solar or wind power at present may actually be contributing to greater use of fossil fuels in some regions. In this paper, we focus on solutions to three approaches to avoid the usage of grid storage: Distributing solar production to minimize its variance, correlation of solar power production to power consumption in air conditioning to determine the upper limits of solar penetration possible without storage, and grid failure probability with different levels of solar penetration.

The paper is organized as follows: Section 2 introduces the method of reducing supply uncertainty via geographic distribution of solar plants; Section 3 introduces the idea of matching solar output with air conditioning consumption and matching wind/solar power output with the consumption of electrical appliances; Section 4 demonstrates the probability of grid failure with different levels of solar penetration; Section 5 supplies concluding remarks.

\section{Reducing supply uncertainty via geographic distribution}

\subsection{Solar power production}

We consider a solar thermal system to produce electricity, in which the solar radiation is first absorbed by the receiver-a tube filled with working fluid (eg. molten salt, $150-350^{\circ} \mathrm{C}$ ) and 
then the absorbed thermal energy is used as a heat source for a power generation system. Our analysis can be easily extended to PV systems - only the constants of proportionality will be different, yielding qualitatively similar results.

We assume flat plate solar collectors for analysis, which can be easily extended to cylindrical parabolic collectors (Singh \& Shama, 2009).

$$
P=A \cdot I \cdot \eta_{1} \cdot \eta_{2} \cdot r,
$$

where $A$ is the total area of collectors, $I$ is the solar radiation intensity, and $\eta_{1}$ is energy transfer efficiency from solar radiation to thermal energy, $\eta_{2}$ is the Carnot Cycle energy transfer efficiency from thermal to mechanical energy, and $r$ is the ratio of efficiency of real heat engine compared to the Carnot Cycle efficiency. We assume that conversion from mechanical to electrical energy is $100 \%$.

The solar-thermal transfer efficiency $\eta_{1}$ can be calculated as:

$$
\eta_{1}=\tau \alpha-U_{L} \frac{T_{H}-T_{a}}{I}
$$

where $\tau$ is the transmissivity, $\alpha$ is the absorptivity listed in Tables 1 and $2 . T_{H}$ is the average temperature of heat transfer fluid (usually melted salt or oil), and $T_{a}$ is the ambient temperature.

\begin{tabular}{|c|c|c|}
\hline Number of covers & $\tau \alpha$ & $U_{L}\left(\mathrm{~kW} / \mathrm{m}^{2} \mathrm{~K}\right)$ \\
\hline 0 & 0.95 & 34 \\
\hline 1 & 0.9 & 5.7 \\
\hline 2 & 0.85 & 3.4 \\
\hline
\end{tabular}

Table 1. Typical flat-plate solar collector (Black) properties

\begin{tabular}{|c|c|c|}
\hline Number of covers & $\tau \alpha$ & $U_{L}\left(\mathrm{~kW} / \mathrm{m}^{2} \mathrm{~K}\right)$ \\
\hline 0 & 0.90 & 28.5 \\
\hline 1 & 0.85 & 2.8 \\
\hline 2 & 0.80 & 1.7 \\
\hline
\end{tabular}

Table 2. Typical flat-plate solar collector(Selective) properties

The Carnot efficiency $\eta_{2}$ in equation (1) is calculated :

$$
\eta_{2}=1-\frac{T_{L}}{T_{H}}
$$

where $T_{L}$ is the lowest cycle temperature (which is slightly greater than ambient temperature $\left.T_{a}\right), T_{H}$ is the highest cycle temperature.

\subsection{The idea of distributed solar power plant}

Solar power plants can produce significant swings of power supply. A cloud passing over a 100MW plant can reduce its output to $20 \mathrm{MW}$, and when it passes over, the output will again swing to 100MW. We develop here the idea of a distributed solar power plant which can ameliorate these swings. Similar work on distribution of wind plants has shown significant 
benefits (Archer \& Jacobin, 2007). The difficulty here is that correlation of solar intensity in locations less than 100 miles from each other will make our quantitative results very different. In the analysis below we assume negligible correlation between solar intensity at multiple locations.

The construction of 10 plants of 10MW each will cause additional capital and maintenance costs. However these may be offset by the benefit of a steadier power supply and less damage to grid equipment. We show how this distribution may be systematically performed.

The power production of the distributed plant $P_{T}$ is the sum of power produced in individual location $P_{i}$ :

$$
P=\sum P_{i}
$$

The variance of power production in the distributed plant is

$$
\sigma_{p}^{2}=\sum_{i=1}^{n} f_{i}^{2} \sigma_{i}^{2}
$$

where $f_{i}=\frac{P_{i}}{P_{T}}, \sigma_{i}^{2}$ is the variance of $P_{i}$, and

$$
\sum_{i=1}^{n} f_{i}=1,
$$

$\sigma_{p}^{2}$ is minimized by the following solution:

$$
f_{i}=\frac{1}{\sigma_{i}^{2}} \frac{1}{\sum_{i=1}^{n} \frac{1}{\sigma_{i}^{2}}},
$$

\subsection{Hypothetical New York example}

We use the historical data of solar intensity of twenty four candidate places within New York state from National Solar Radiation Data Base (NSRDB, 2005), and the corresponding temperature data from the United States Historical Climatology Network (USHCN, 2005). Then we choose four places of maximum annual solar intensity: Islip Long Island Macarthur Airport, John F Kennedy Intl Airport, New York Laguardia Airport and Republic Airport, and label them as area A, B, C and D. Fig. 1 shows the hourly average solar radiation of a typical day within each month. To construct synthetic time series of solar data, we proceeded as follows: Use random samples $x_{k}$ from the data of solar intensity distribution between 2001-2005 every $T=36$ seconds and use a low pass filter with a time constant $\tau=180$ seconds. A valid question that may be asked here is - what is the benefit if solar intensity is strongly correlated between different locations? Our calculation of the covariance matrix of solar intensity for June, 2005 using hourly observations each day yields 30 difference covariance matrices for 30 days in June, 2005. The ratio of standard deviation to mean solar intensity of the corresponding eigenvalues of these 30 matrices range from 0.4681 to 0.8283 indicates a varying solar intensity distribution for different days. The ratio of the difference between eigenvalues and diagonal elements over diagonal elements range from -2.6496 to 0.9858 indicates a strong correlation of these four cites. However, in this discussion, we just neglect the correlation among these four cites. This opens up problems for future work which we discuss in the conclusions. 

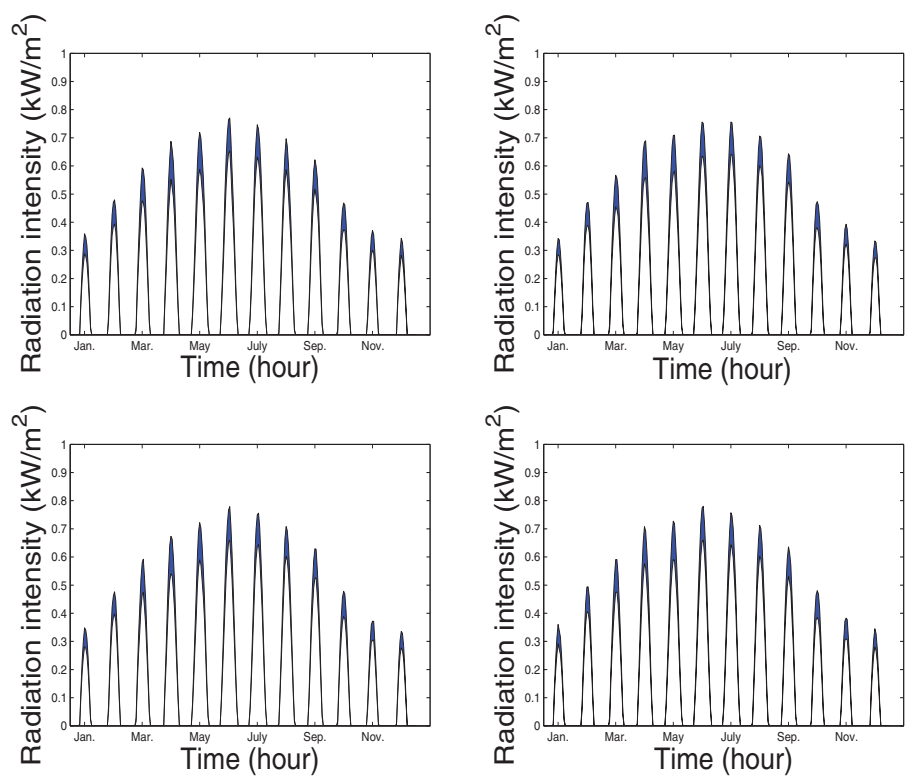

Fig. 1. Radiation intensity

The low pass filter smooths out jumps in intensity so they mimic what the motion of a cloud produces. The $\mathrm{X}$ axis in Fig. 1 is formed by one day from each month (24hr.12month).

The data of hourly average temperature of a typical day within each month is acquired from United States Historical Climatology Network (USHCN, 2005). Fig. 2, 3 and 4 show respectively the electric power outputs of the central plants in one location $\left(16000 \mathrm{~m}^{2} \times 1\right)$, evenly in two locations $\left(8000 \mathrm{~m}^{2} \times 2\right)$, and evenly in four locations $\left(4000 \mathrm{~m}^{2} \times 4\right)$. Fig. 5 shows the power output of the optimally distributed plants. Fig. 6 gives the relationship between the coefficient of deviation and the installment cost. $Y_{1}$ axis represents the natural log of coefficient of deviation, $Y_{2}$ axis represents the natural log of setup cost. We can see from the figure that as the number of locations increases, the coefficient of deviation decreases, while the setup cost increases.

\section{Supply-demand matching mechanisms}

\subsection{Matching solar production to air conditioner consumption}

The electricity load in the hot season vs temperature for a large commercial facility in New York (Luo et al, 2009) in June, 2007 is shown in Fig. 7. The $X$ axis is the temperature in ${ }^{o} F$, and $\mathrm{Y}$ axis is the electricity consumption in $\mathrm{kWh}$. It is reasonable for the temperature and the load to have positive relation because in summer, the great portion of electricity consumption is due to air conditioning. Therefore the energy consumption of the building from the plot can be expressed as:

$$
q_{p}=a_{1} \times T+a_{2}
$$



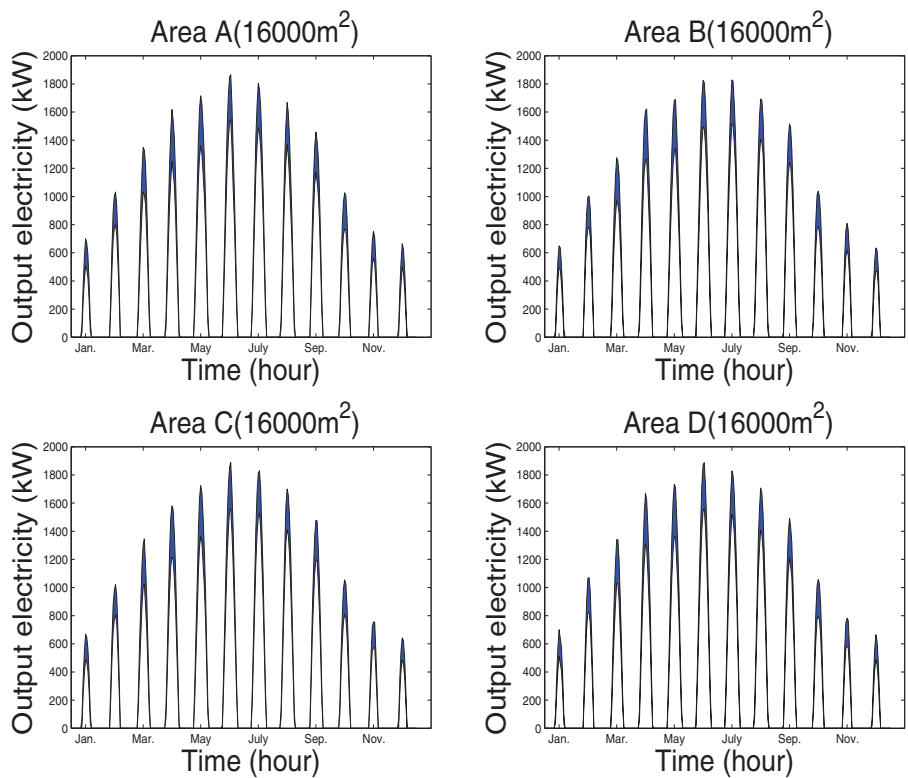

Fig. 2. Electricity output by CSP of area $16000 m^{2} \times 1$
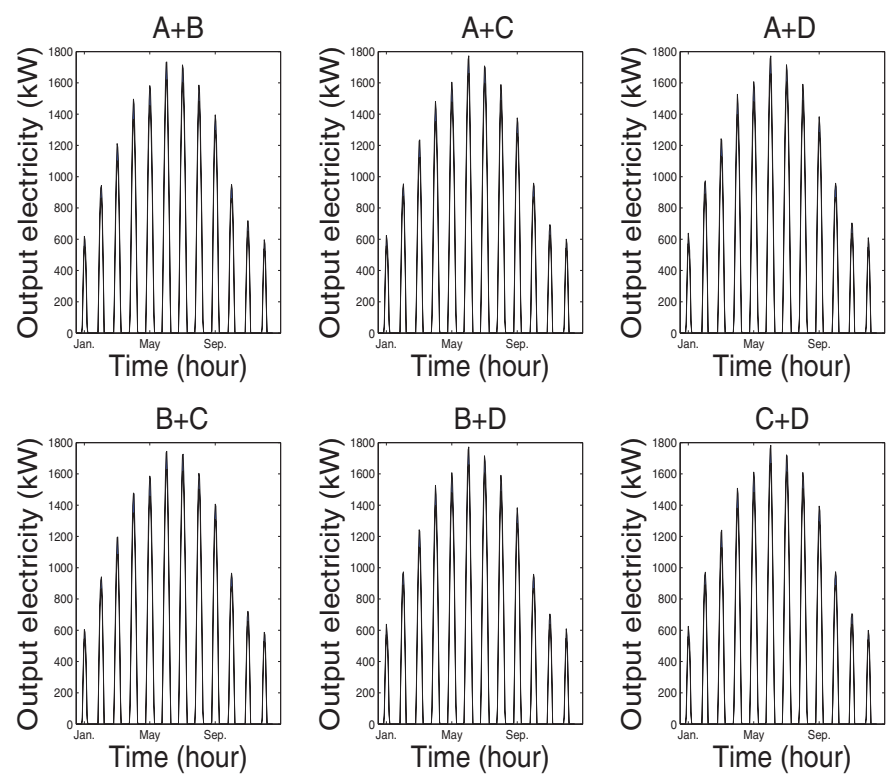

Fig. 3. Electricity output by CSP of area $8000 m^{2} \times 2$ 


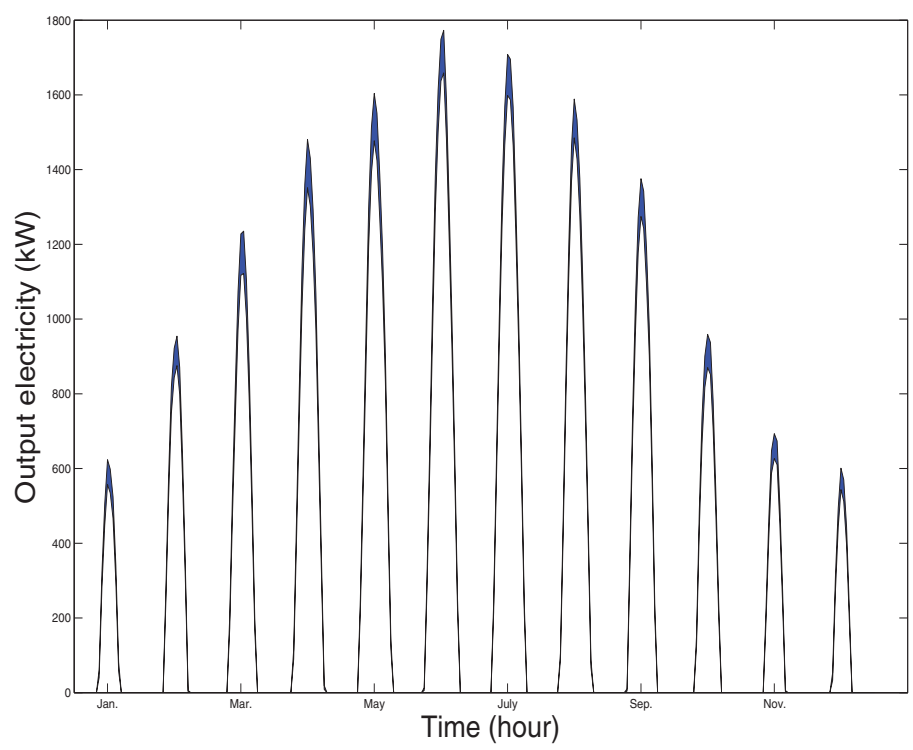

Fig. 4. Electricity output by CSP of area $4000 m^{2} \times 4$

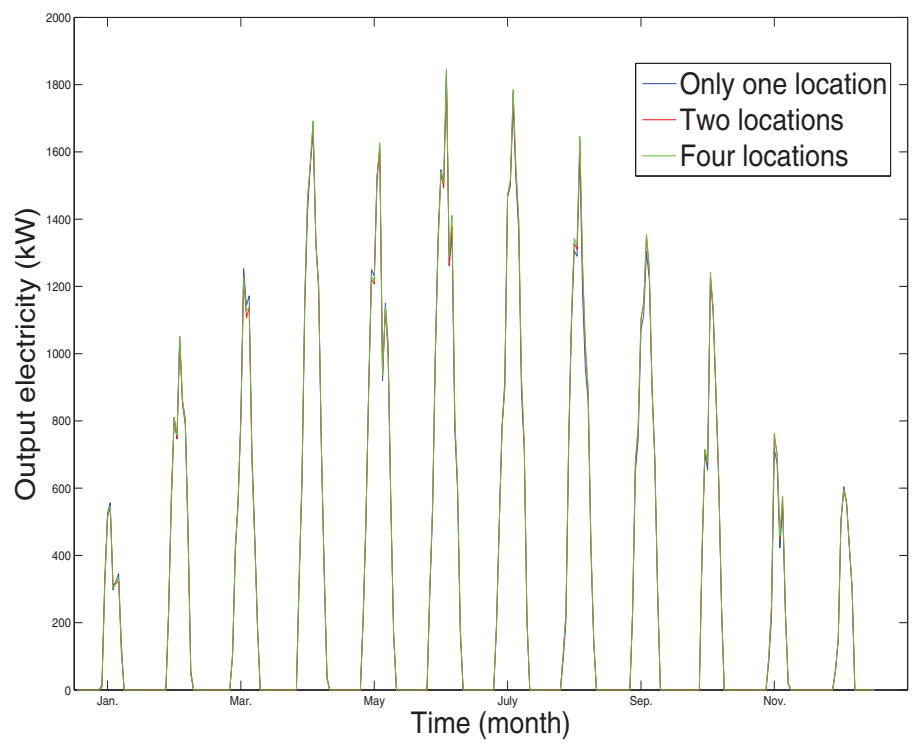

Fig. 5. Optimal electricity output by CSP of area located in four places 


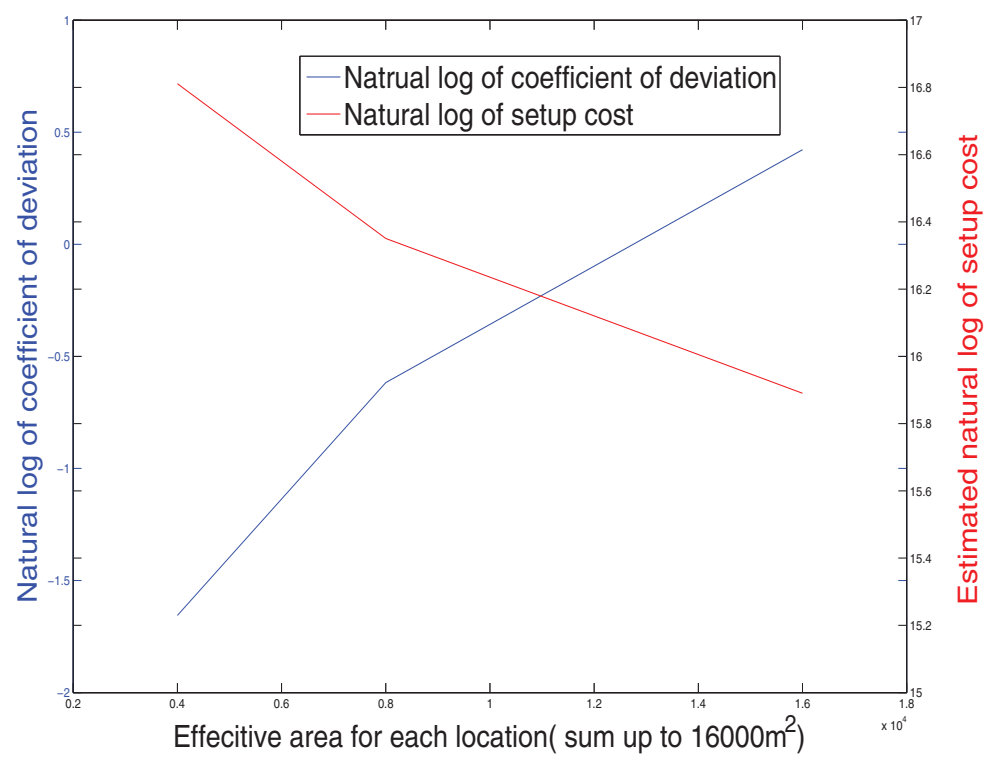

Fig. 6. Coefficient of deviation vs cost

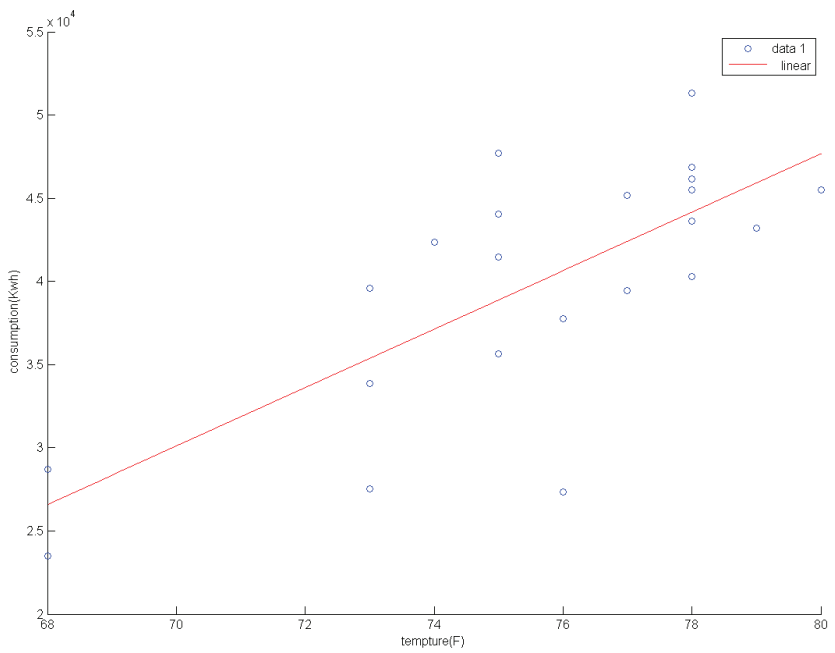

Fig. 7. Electricity consumption versus temperature in summer 


$$
\begin{gathered}
C_{p}=\sum\left(a_{1} \times T+a_{2}-D_{s}\right) P_{e}+C S P_{f}+\sum D_{s} C S P_{v} \\
a_{1}=1756.9, a_{2}=-92880
\end{gathered}
$$

Where $q_{p}$ is the predicted energy consumption, $C_{p}$ is the predicted bill, $D_{s}$ is the solar energy output, $P_{e}$ is the electricity price, $C S P_{f}$ is the fixed CSP maintenance cost, and $C S P_{v}$ is the CSP cost that may vary according to the solar energy output. The reason the correlation of power consumption to temperature is not very strong in Fig. 7 is that, for the commercial facility , air conditioning consumption is a large but not the dominant part of consumption.

This idea comes from the simple fact that as the solar intensity increases, both the CSP output and the air conditioner consumption increase, so we can match them to achieve an energy balance. The advantage of this matching may include: reduce the need for base load plants, and integrating solar power stably into the grid base.

Fig. 8 gives the electricity consumption of air conditioner of 10000 families (with room area uniformly distributed within $80 \mathrm{~m}^{2}-160 \mathrm{~m}^{2}$ and power of air conditioner uniformly distributed within $0.8 \mathrm{~kW}-1.6 \mathrm{~kW})$. It is calculated using active energy management described in previous work (Luo et al, 2009). We can see by comparing Fig. 5 and Fig. 8 that in summer, they have similar envelopes. The AC consumption flattens out because of the on-off nature of the control through thermostats.

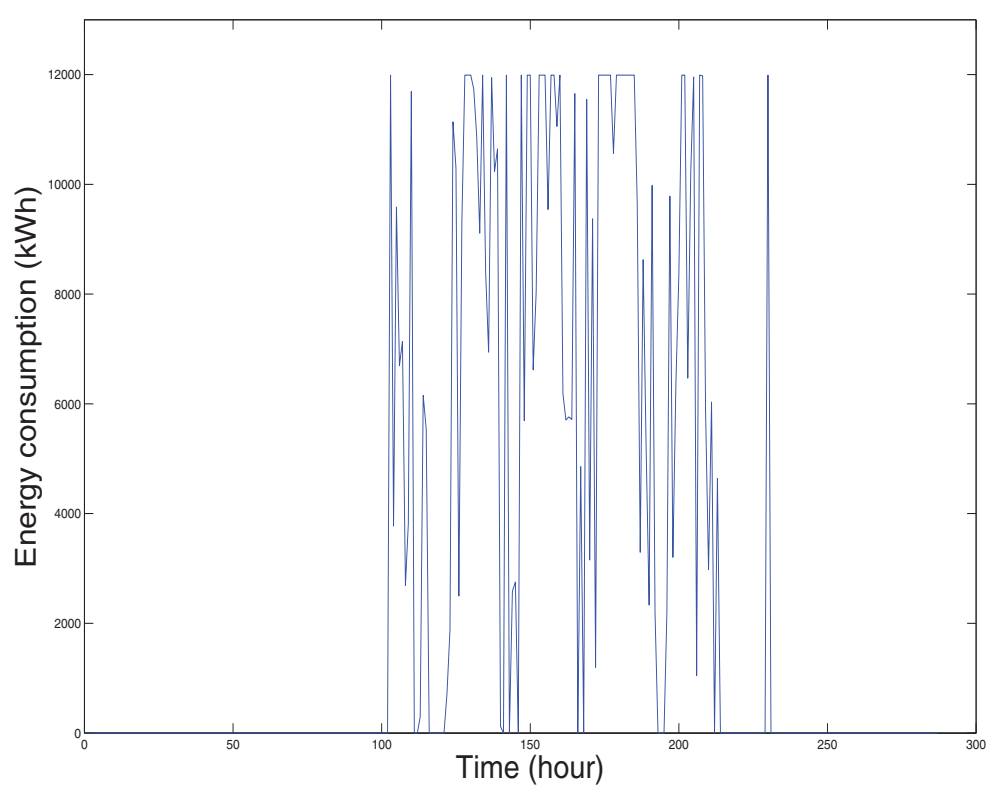

Fig. 8. AC consumption of 10000 families 


\begin{tabular}{|c|c|c|c|}
\hline Applicance & Power $(\mathrm{kW})$ & Hours & Energy $(\mathrm{kJ})$ \\
\hline Water heater (40 gallon) & 5 & 7 & 35 \\
\hline Clothes Dryer & 4.5 & 2 & 9 \\
\hline Dishwasher & 0.2 & 3.5 & 7 \\
\hline Hair dryer & 1.6 & 5 & 8 \\
\hline Clothes iron & 1.6 & 2 & 3.2 \\
\hline Vacuum cleaner & 1.3 & 2 & 2.6 \\
\hline Toaster & 1.3 & 3 & 3.9 \\
\hline Coffee maker & 1.1 & 2 & 2.2 \\
\hline Refrigerator & 0.7 & 50 & 35 \\
\hline Personal computer & 0.27 & 32 & 8.6 \\
\hline Televisions & 0.15 & 20 & 3 \\
\hline
\end{tabular}

Table 3. Weekly energy consumption of home appliances

\subsection{Household appliance consumption periodicity}

Similar ideas can work for matching electronics appliances consumption and wind or solar energy output. Energy consumption of most appliances like dish washer/dryer have relatively constant frequencies and phases-although these may vary from family to family - since most people have the habit of washing their dishes and clothes at regular time of every week. This gives us the idea to describe the energy consumption of different electronics appliances with pulses of different frequencies and phases uniformly distributed over their respective ranges.

For a typical American family of four people, we have the room properties as in Table 3. In Fig. 9 we have shown the energy consumption distribution. We represent the energy consumption of the electronics applicants of each family with rectangle pulse train, and Fig. 10 gives the combination results of energy consumption of 100, 000 families.

So long as the total production from wind or solar as the renewable source equals consumption from the appliances within the period of consideration--such as a few hours or a day- it is theoretically possible, via pricing, to match supply and demand.

\section{Grid dynamics and control with solar power penetration}

\subsection{Grid dynamics and control model}

Traditional grid dynamics models have been discussed in various books (Murty, 2008), (Machowski et al, 2008). The flow chart 11 below gives the Gauss-Seidel iterative method for load flow solutions for a $\mathrm{n}$ bus system with 1 slack bus. In this flow chart, $\mathrm{P}$ is the real power in $\mathrm{kW}$ while $\mathrm{Q}$ is reactive power in kVar. In real system, in order to secure the grid system, we need constrains in this dynamics model such as:

- Current in any of $\mathrm{n}$ buses must not exceeds the limit $I_{\text {limit }}$ in order to prevent blackout in the system.

- Calculated reactive power must not exceed the limits that local reactive power station can provide. If so, reactive power is fixed at the limit that is violated and it is no longer possible to hold desired bus voltage. 


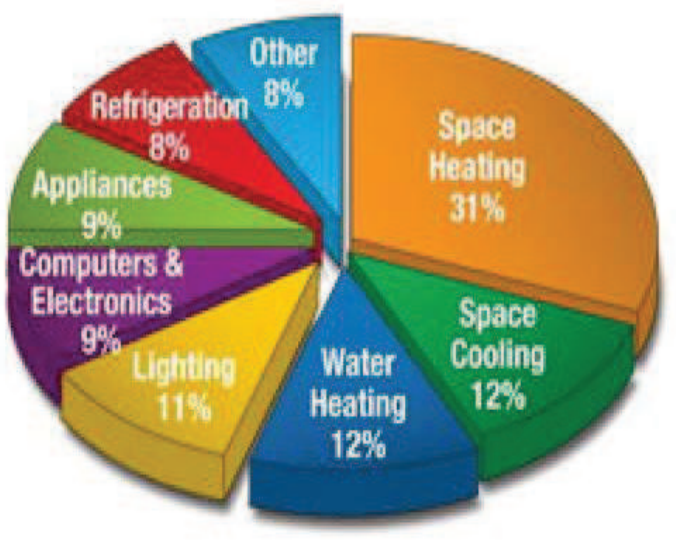

Fig. 9. Residential electricity consumption

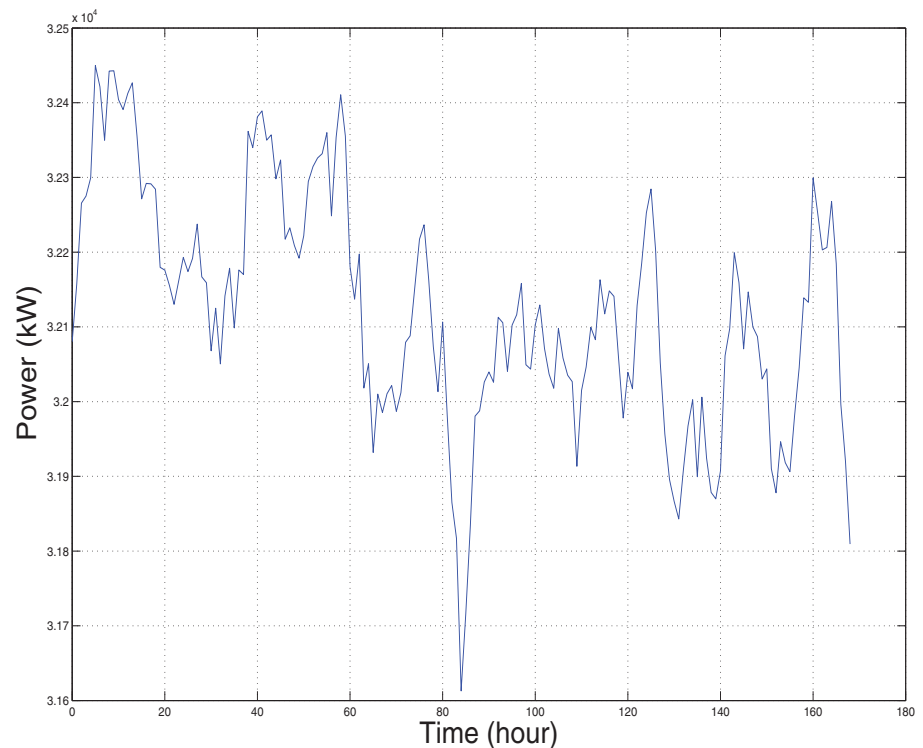

Fig. 10. Residential power consumption of 10000 families 


\begin{tabular}{|c|c|}
\hline Action/Operation & Time Frame \\
\hline Wave effects(fast dynamics, lighting-caused overvoltages) & Microseconds to milliseconds \\
\hline Switching overvoltages & Milliseconds \\
\hline Fault protection & 100 ms \\
\hline Slectromagnetic effects in machine windings & Milliseconds to seconds \\
\hline Stability augmentation & 1 seconds \\
\hline Electromechanical effects of oscillations in motors \& generators & Milliseconds to minutes \\
\hline Tie line load frequency control & $1-10$ seconds, ongoing \\
\hline Economic load dispatch & 10 seconds-1 hour, ongoing \\
\hline Thermodynamic changes from boiler control action & Seconds to hours \\
\hline System structure monitoring & 1 hr- 1 day \\
\hline System state estimation & $1-10$ seconds \\
\hline Security monitoring & 1 minute to 1 hour \\
\hline Load management, forecasting & 1 hour to 1 day, ongoing \\
\hline Maintenance scheduling & Months to 1 year, ongoing \\
\hline Expansion planning & Years, ongoing \\
\hline Power plant building & $2-10$ years, ongoing \\
\hline
\end{tabular}

Table 4. Control Time Scales (Abdallah, 2009)

- The state of change of the voltage must not exceed the slow state of the generator+tie line voltage control. Otherwise we have control saturation and the generator can no longer track the changes.

Table 4 gives the time scale of different disturbances and control signals in the grid. Once the disturbance introduced to the grid system exceeds the control limit, the cascading failure will happen (Ding et al, 2011). The test case (Dusko et al, 2006) in Fig. 12 and Fig. 13 represent a large European power system and has 1000 buses, 1800 transmission lines and transformers, and 150 generating units. The base case load has an active power demand of $33 \mathrm{GW}$ and a reactive power demand of 2.5 GVar. It is seen from 12 that there is a sharp increase in blackout size at the critical loading of 1.94 times the base case loading, and (Dusko et al, 2006) also discussed that the expected energy not served (EENS) share similar distribution for critical loading and under critical loading cases, and for over critical loading cases, we have different patterns, with the exponent of the power law distributions ranging from -1.2 to -1.5 as shown in Table. 5.

\subsection{Grid fluctuation introduced by different levels of solar penetration}

A report published in 2009 by the North American Electric Reliability Corporation showed that the output power of a large PV systems, with ratings in the order of tens of megawatts, can change by $\pm 70 \%$ in a five- to ten-min time frame (NAERC, 2009). And it should also be mentioned that if a number of small systems that are distributed over a large land area, the resulting combined fluctuations are much less due to the smoothing effect according to our previous analysis. 


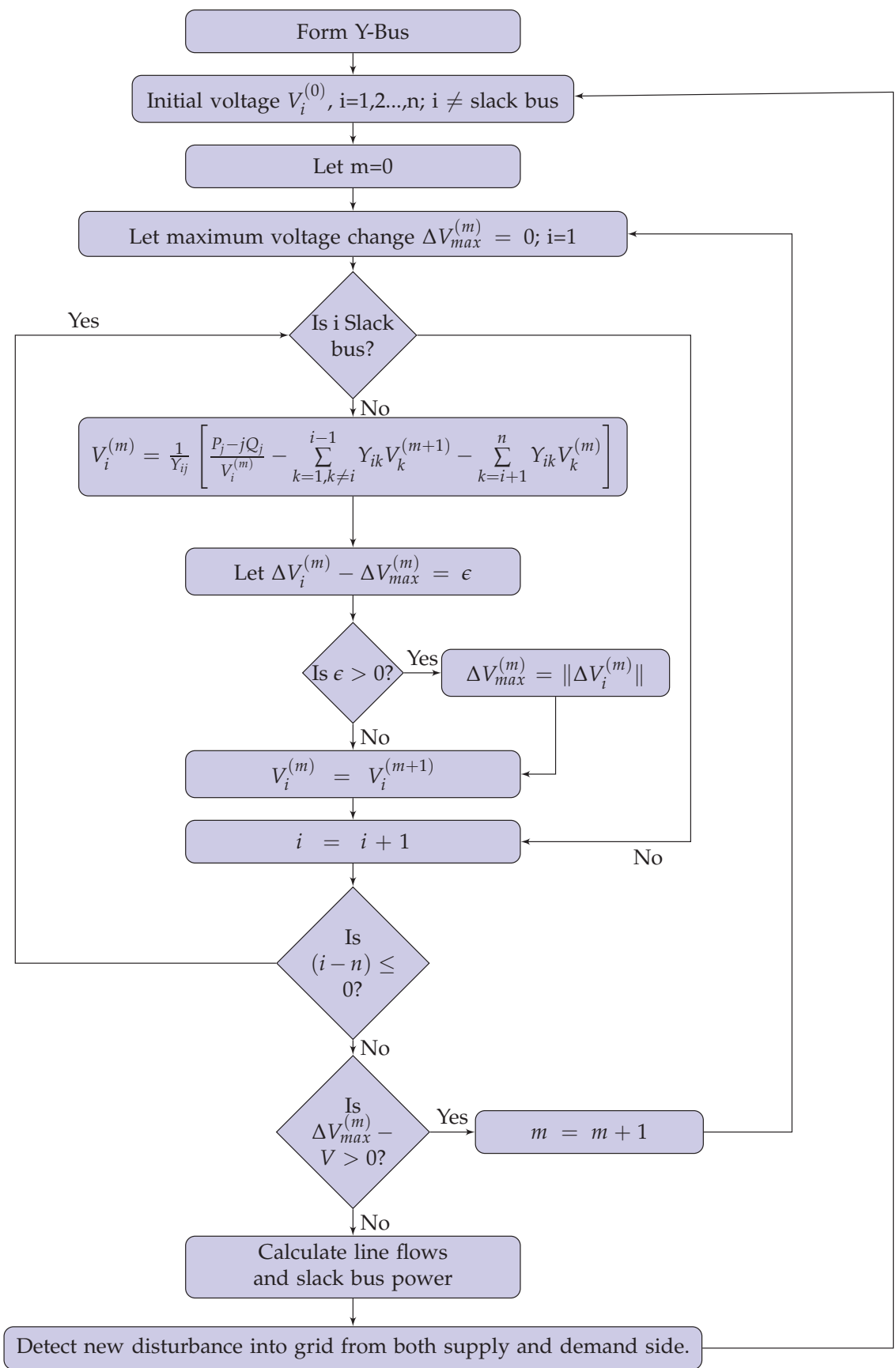

Fig. 11. Flow chart of Gauss-Seidel iterative method for load flow solutions for a $\mathrm{n}$ bus system with 1 slack bus 


\begin{tabular}{|c|c|c|c|}
\hline Model & Exponent & Test Case & Reference \\
\hline OPA & $-1.2,-1.6$ & - & (Carreras et al, 2004) \\
\hline Branching & -1.5 & - & (Dobson et al, 2004) \\
\hline CASCADE & -1.4 & 1000 buses & (Dobson et al, 2005) \\
\hline Hidden Failure & -1.6 & - & (Chen et al, 2005) \\
\hline Manchester & $-1.2,-1.5$ & - & (Dusko et al, 2006) \\
\hline
\end{tabular}

Table 5. Approximate power law exponents at criticality for several cascading failure models

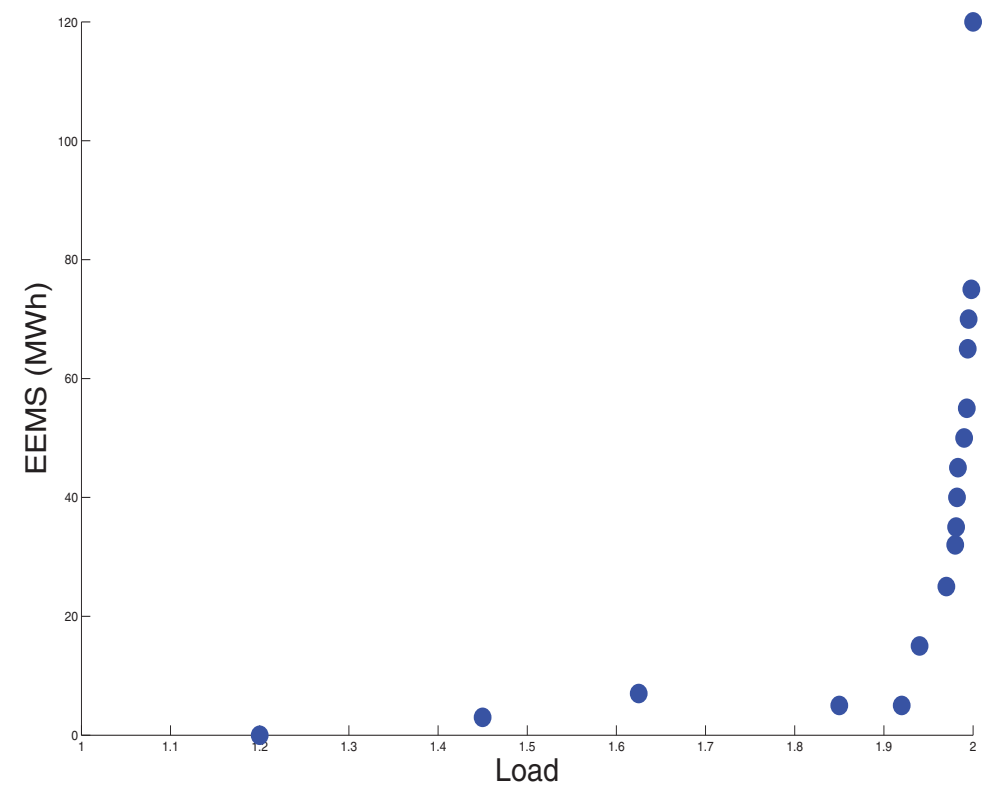

Fig. 12. Expected energy not served (EENS) as a function of the loading factor with respect to the base case. (Dusko et al, 2006)

Fig. 14 shows an example of the PV output fluctuations in New York area, it is a normal distribution with a mean plot and a confidence interval of $68 \%( \pm 1 \sigma)$. Here we assume the PV output fluctuation have similar distribution with the solar radiation, which is reasonable according to the solar power output model (Dusabe et al, 2009). The $X$ axis of the figure is time in hours and $\mathrm{Y}$ axis is the system output in MWh. We can conclude from this figure that the most severe fluctuation occurs around noon. In general, the change of solar power output is usually due to:

- Time of the day.

- Time of the year.

- PV system locations. 


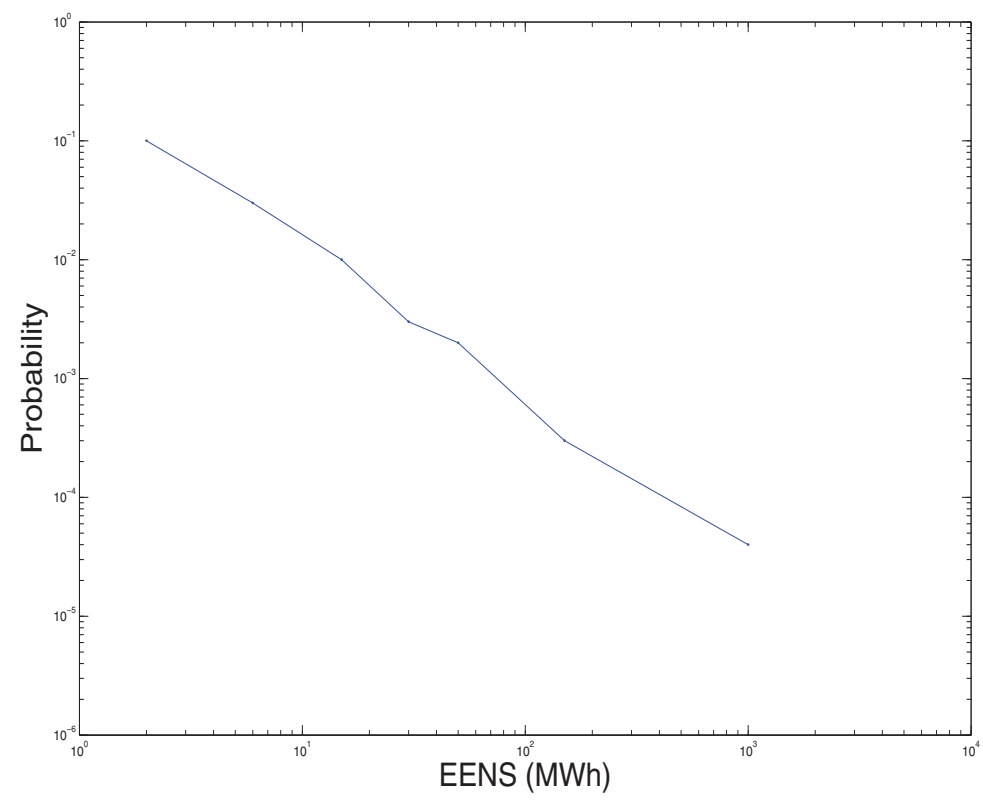

Fig. 13. Probability distribution of expected energy not served (EENS) at the critical loading of 1.94 times the base case loading (Dusko et al, 2006)

- Types of Clouds.

- PV system topology.

The negative effects introduced, especially to the stability of grid system as solar penetration level increases, is a major concern for the future grid. We can calculate the blackout probability of power system with different level of solar penetration as following:

For a grid system with $a \%$ of power from solar system, which follows a normal distribution:

$$
W_{\text {solar }} \sim N\left(a \%, \sigma_{(a, i)}^{2}\right), i=0,1 \ldots 23
$$

where $a \%$ is the normalized expected power output from PV system at $i^{\text {th }}$ hour of the day with $a \%$ of penetration for the overall grid system, and $\sigma_{(a, i)}$ is the standard deviation of power output at the same time and same penetration level.

We can equate the solar system fluctuation to the inverse change of loading, for instance, a decrease of $1 M W h$ of solar production is equivalent to an increase of the power load at the same time frame, therefore the equivalent load should also follow normal distribution.

$$
L \sim N\left(l, \sigma_{(a, i)}^{2}\right)
$$




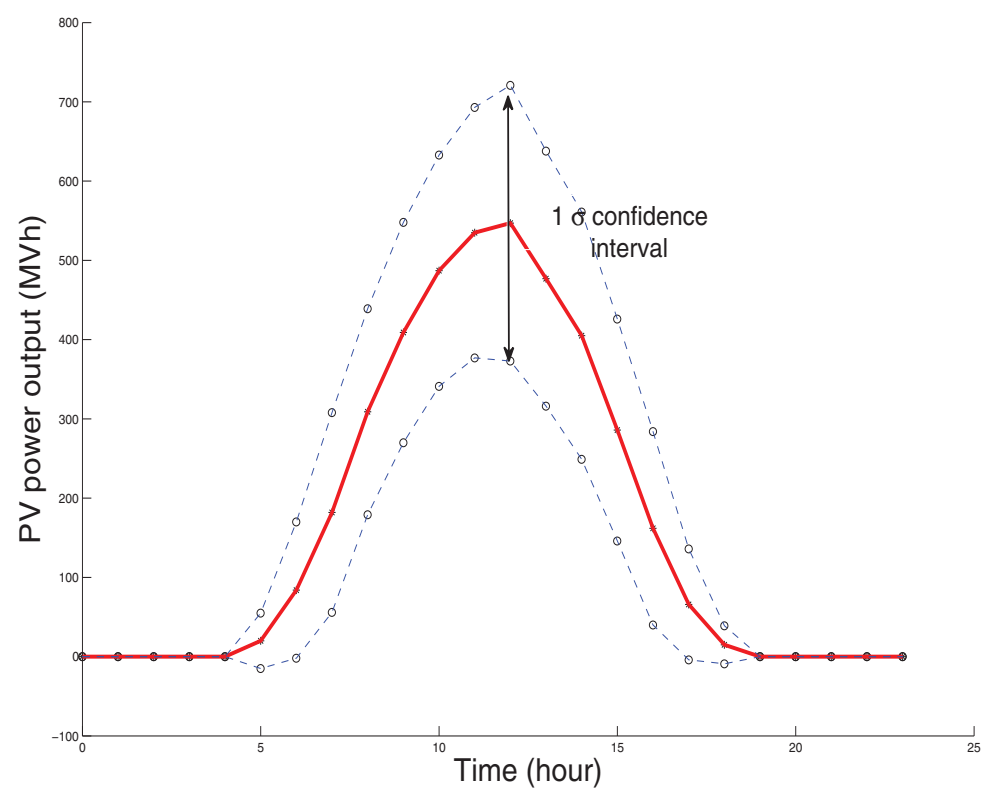

Fig. 14. Fluctuations in the output power of a large PV system ( $1 \sigma$ confidence interval) (NSRDB, 2005)

then following the same procedure as in Fig. 12 and Fig. 13, probability of failure due to different level of solar penetration is

$$
P_{(f, a)}=\int_{-\infty}^{\infty} p_{(L, a)} F_{(E E N S>0 \mid(L, a))} d L
$$

where the probability $F_{(E E N S>0 \mid(L, a)}$ is the cumulative probability distribution of system failure

$$
F_{(E E N S>0 \mid(L, a))}=\int_{0}^{\infty}\left(p_{(E E N S, L, a)}\right) d E E N S
$$

and $p_{(E E N S, L, a)}$ is the probability density function in Fig. 13 , in this example, $L=1.94$ and $a=0$.

For instance, if we choose $i=12$, when solar radiation follows $\mathrm{N}(547,174)$, and assume solar system output follows the same distribution. The normalized solar penetration of $a=1,10,50,100$, and corresponding standard deviation of solar system output $\sigma_{(a, i)}=0.0027$, $0.0269,0.1344,0.2687$. And the grid failure model with these levels of solar penetration is shown in Fig. 15, in which we show that as the level of solar penetration increases, the probability of system failure increases. This analysis does not take into account, additional solar backup. Thus as the proportion of solar power increases, the proportion of a controllable base load power source to meet demand fluctuations reduces, and hence, the system becomes more prone to failure. The availability of storage can ameliorate the problem. Fig. . 15 does not take into account real time matching of AC demand with solar supply, which and reduce failure probability. 


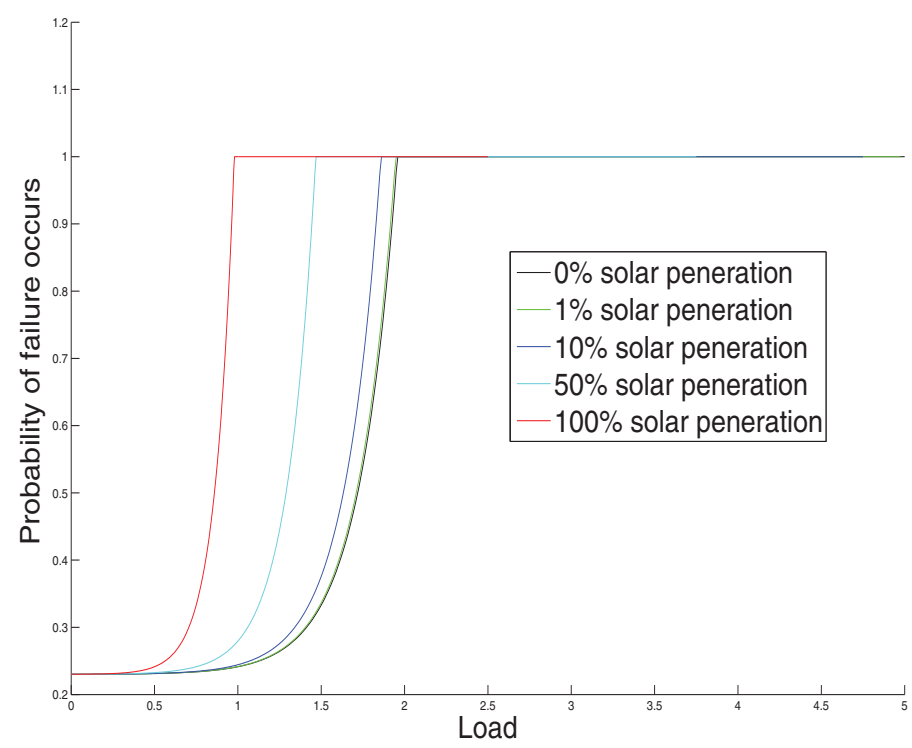

Fig. 15. Probability of system failure with different levels of solar penetration

\section{Concluding remarks}

We have supplied a partial proof of concept for two methods of reducing supply-demand imbalance. First, we have shown that the effect on power production of distributing solar plants - the coefficient of deviation is reduced by $50 \%$ in our example. If we were to consider covariance of energy production on different locations, our optimization problem for distribution could be extremely complicated, given that the covariance varies from day to day and from season to season. We will address this in future work, as the issue will obscure presentation of the basic idea here. Our calculations show that solar production and AC power consumption are strongly correlated. Hence, solar production could penetrate the grid to the extent of replacing the peaker gas turbine plants that the utilities use for peak usage in summer. Finally, we have shown by use modeling of aggregate demand of household appliances that it is possible to use solar or wind power as it gets produced. Whenever there is availability of solar power on the grid, smart appliances can switch on and use it.

Our ultimate objective is to reduce the unpredictability of supply-demand in the grid as solar power penetration increases, with minimal use of expensive, limited life grid storage. While the solution approaches we have proposed show how this can be done in theory, they ignore the transients that depend upon the speed of sensing supply and matching it with demand. The main requirement for stability in the grid is the matching of phase from various sources over a reactive time scale and load scheduling over the tactical time scale (minutes to hours). High speed measurements are available for both grid voltage and current. The movement of clouds is also reasonably predictable in short interval of less than hours. This will ensure that a utility can fire up a base load coal or steam turbine 3 hours before it is necessary or a gas turbine 15 minutes before it is necessary. 
The utility industry is extremely conservative and will not make changes that can destabilize the grid. Even in Germany, solar penetration has not exceeded 2\% inspect of significant taxpayer subsidies. What we have shown is that specific guarantees of safety can be constructed for various levels of solar penetration-whether distributed or centralized. Once we construct these guarantees, grid penetration of solar power could perhaps reach $10 \%$ even without advances in battery or thermal storage technology.

\section{References}

Abdallah, C.T.(2009). Electric Grid Control: Algorithms E Open Problems, available at http: // ElectricGridControl: Algorithms\&OpenProblems.

Archer, C. and Jacobin, M. Z.(2007). Supplying Baseload Power and Reducing Transmission Requirement by Interconnecting Wind Farms, Journal of Applied Meteorology and Climatology Volume 46.

Carreras BA, Lynch VE, Dobson I, Newman DE(2004). Complex dynamics of blackouts in power transmission systems. Chaos; 14(3), 43-52.

Chen J, Thorp JS, Dobson I. Cascading dynamics and mitigation assessment in power system disturbances via a hidden failure model. International Journal of Electrical Power $\mathcal{E}$ Energy Systems27(4):318-26.

Ding L., Cao Y., Wang W., Liu M.(2011), Dynamical model and analysis of cascading failures on the complex power grids. Kybernetes, Vol. 40 Issue 5, 814-823.

Dobson I, Carreras BA, Newman DE (2004). A branching process approximation to cascading load-dependent system failure. Hawaii International Conference on System Sciences, Hawaii, USA.

Dobson I, Carreras BA, Newman DE(2005). A loading-dependent model of probabilistic cascading failure. Probability in the Engineering and Informational Sciences. 19(1), 515-32.

US Department of Energy. Energy Efficiency Trends in Residential and Commercial Buildings, available at: http://http://apps1.eere.energy.gov/buildings/ publications/pdfs/corporate/bt_stateindustry.pdf

US Department of Energy. Smart Grid System Report, available at: http: / /www . smartgrid. gov/sites/default/files/resources/systems_report.pdf

Dusabe, D., Munda, J., Jimoh, A.(2009). Modelling of cloudless solar radiation for PV module performance analysis. Journal of Electrical Engineering, Vol. 60, NO. 4, 192-197.

Dusko P. N, Dobson I, Daniel S. K., Benjamin A. C. and Vickie E. L.(2006). Criticality in a cascading failure blackout model. Electrical Power and Energy Systems, 28 (2006): 627-633

Luo, Q., Ariyur, K. B. and Mathur A. K.(2009), Real Time Energy Management : Cutting the Carbon Footprint and Energy Costs via Hedging, Local Sources and Active Control, ASME 2009 Dynamic Systems and Control Conference, Vol. 1, 157-164 .

Machowski, J., Bialek, J and Bumby, B.(2008). Power System Dynamics: Stability and Control second edition. Jon Wiley \& Sons, Ltd. IBSN: 9780470725580

Murty,PRS.(2008). Operation and Control in Power Systems, first edition. BS Publications. IBSN: 9788178001810

North American Electric Reliability Corp.(2009). Accommodating High Levels of Variable Generation. Available:

http: / /www.nerc.com/files/IVGTF_Report_041609.pdf

Solar Intensity Data is from National Solar Radiation Data Base, available at: http://rredc.nrel.gov/solar/old_data/nsrdb/ 
Nuqui, R.(2009). Electric Power Monitoring with Synchronized Power Measurements, first edition, VDM Verlag Dr. Muller, ISBN-10: 3639116399

Srivastava, A. and Flueck, A.(2008). Contingency Screening Techniques And Electric Grid Vulnerabalities, first edition, VDM verlag, ISBN-10: 3836487012

Singh K.D.P.and Shama S.P.(2009). Enhancement in Thermal Performance of Cylindrical Parabolic Concentrating Solar Collector, ARISER Vol. 5 No. 1, 41-48

Temperature data is from United States Historical Climatology Network, availabel at: http : / / cdiac.ornl.gov/epubs/ndp/ushen/ushcn.html 


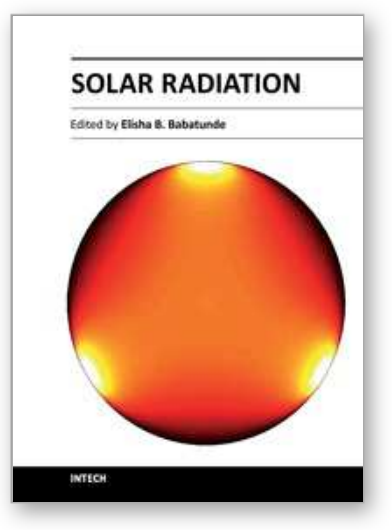

\author{
Solar Radiation \\ Edited by Prof. Elisha B. Babatunde
}

ISBN 978-953-51-0384-4

Hard cover, 484 pages

Publisher InTech

Published online 21, March, 2012

Published in print edition March, 2012

The book contains fundamentals of solar radiation, its ecological impacts, applications, especially in agriculture, architecture, thermal and electric energy. Chapters are written by numerous experienced scientists in the field from various parts of the world. Apart from chapter one which is the introductory chapter of the book, that gives a general topic insight of the book, there are 24 more chapters that cover various fields of solar radiation. These fields include: Measurements and Analysis of Solar Radiation, Agricultural Application / Bio-effect, Architectural Application, Electricity Generation Application and Thermal Energy Application. This book aims to provide a clear scientific insight on Solar Radiation to scientist and students.

\title{
How to reference
}

In order to correctly reference this scholarly work, feel free to copy and paste the following:

Qi Luo and Kartik B. Ariyur (2012). Utility Scale Solar Power with Minimal Energy Storage, Solar Radiation, Prof. Elisha B. Babatunde (Ed.), ISBN: 978-953-51-0384-4, InTech, Available from:

http://www.intechopen.com/books/solar-radiation/utility-scale-solar-power-with-minimal-energy-storage

\section{INTECH}

open science | open minds

\section{InTech Europe}

University Campus STeP Ri

Slavka Krautzeka 83/A

51000 Rijeka, Croatia

Phone: +385 (51) 770447

Fax: +385 (51) 686166

www.intechopen.com

\section{InTech China}

Unit 405, Office Block, Hotel Equatorial Shanghai

No.65, Yan An Road (West), Shanghai, 200040, China

中国上海市延安西路65号上海国际贵都大饭店办公楼 405 单元

Phone: +86-21-62489820

Fax: +86-21-62489821 
(C) 2012 The Author(s). Licensee IntechOpen. This is an open access article distributed under the terms of the Creative Commons Attribution 3.0 License, which permits unrestricted use, distribution, and reproduction in any medium, provided the original work is properly cited. 